\title{
Envelhecimento populacional e políticas públicas : desafios para o Brasil no século XXI
}

Population ageing and public policies: Brazil's challenges in the XXI century Viellissement démographique et politiques publiques : défis pour le Brésil au XXI ${ }^{e}$ siècle

Envejecimiento de la poblaciòn y politicas publicas: desafio para el Brasil del siglo $x x i$

\section{Antônio Tadeu Ribeiro de Oliveira}

\section{(2) OpenEdition}

\section{Journals}

\section{Edição electrónica}

URL: http://journals.openedition.org/espacoeconomia/2140

DOI: 10.4000/espacoeconomia.2140

ISSN: 2317-7837

\section{Editora}

Núcleo de Pesquisa Espaço \& Economia

\section{Refêrencia eletrónica}

Antônio Tadeu Ribeiro de Oliveira, «Envelhecimento populacional e políticas públicas : desafios para o Brasil no século XXI », Espaço e Economia [Online], 8 | 2016, posto online no dia 23 setembro 2016, consultado o 30 abril 2019. URL : http://journals.openedition.org/espacoeconomia/2140 ; DOI : 10.4000/espacoeconomia.2140

Este documento foi criado de forma automática no dia 30 Abril 2019.

(C) NUPEE 


\title{
Envelhecimento populacional e políticas públicas : desafios para o Brasil no século XXI
}

\author{
Population ageing and public policies: Brazil's challenges in the XXI century \\ Viellissement démographique et politiques publiques : défis pour le Brésil au XXI \\ ${ }^{e}$ siècle \\ Envejecimiento de la poblaciòn y politicas publicas: desafio para el Brasil del \\ siglo $x \times i$
}

Antônio Tadeu Ribeiro de Oliveira

\section{Introdução}

1 O Brasil, desde dos anos 1980, atravessa uma etapa na sua dinâmica populacional conhecida como "bônus demográfico" ou "janela de oportunidade demográfica". Mas, o que viria a ser isto? Significa que, face ao declínio dos níveis de fecundidade, a inércia demográfica provoca o aumento significativo da população em idade ativa (15 a 64 anos) e, consequentemente, a razão de dependência total diminui. Nesse cenário, potencialmente, teríamos um contingente maior de pessoas em idade de trabalhar quando comparado aos segmentos mais jovens ( 0 a 14 anos) e dos idosos (65 anos ou mais), ou seja, a dependência daqueles que teoricamente não estariam fazendo parte da força de trabalho seria menor.

2 Essa fase da transição demográfica deveria, em tese, impulsionar o desenvolvimento econômico e social, além de gerar riqueza e poupança interna. Favoreceria também a melhoria na qualidade da educação básica, sobretudo pelo fato da menor demanda por recursos para investimentos em infraestrutura. Não obstante, como no início da abertura da "janela de oportunidades" a população idosa ainda é pequena, a pressão sobre os sistemas de proteção social, aí incluídas saúde e seguridade, não seria grande. 
3 Contudo, parece que nada saiu como deveria. A primeira década de "bônus demográfico" ficou conhecida como a "década perdida". O país só começou a retomar o desenvolvimento econômico em meados dos anos 1990, de modo que muito pouco foi aproveitado nos primeiros 15 anos. Os gargalos estruturais, entre outros, na educação, saúde, saneamento básico, mercado de trabalho e infraestrutura produtiva, agravados pela implementação de um modelo neoliberal de desenvolvimento, contribuíram para inibir ainda mais o aproveitamento das vantagens oferecidas pela dinâmica populacional brasileira.

4 Nos dias de hoje, trinta e cinco anos após o início do "bônus", um olhar mais crítico sobre os aspectos da vida social e econômica não consegue enxergar os resultados esperados da inércia demográfica. Nos próximos anos, estima-se que a "janela de oportunidades" começará a se fechar, tendo em vista o continuado processo de redução dos níveis da fecundidade e o aumento da longevidade, sendo o envelhecimento populacional um fato concreto a exigir uma resposta da sociedade brasileira.

5 A proposta deste artigo é reivindicar um espaço de discussão e reflexão sobre o tema, evitando que uma questão de fundamental importância para o desenvolvimento social e econômico do país fique relegada a um segundo plano. Em primeiro lugar, se contextualiza os efeitos da transição demográfica no presente e num futuro próximo, para, em seguida, apresentar os aspectos estruturais que devem ser tratados de modo que políticas públicas e populacionais possam ser implementadas de forma a enfrentar as questões associadas ao envelhecimento populacional, numa perspectiva de projeto de nação baseado na adoção de medidas econômicas e sociais universais e inclusivas.

\section{A tendência demográfica e os indicadores implícitos pós-1980}

6 É importante ratificar, com os números das projeções de população oficiais, as tendências demográficas apontadas para as próximas décadas (IBGE, 2013). Os cenários mais realistas, possíveis de serem construídos nos dias de hoje, sinalizam para a continuada redução dos níveis de fecundidade e para o aumento da longevidade da população brasileira. A combinação desses dois aspectos leva ao envelhecimento de nossa sociedade, fenômeno que não diz respeito só ao Brasil, mas parece ser a tendência dos países desenvolvidos e em boa parte daqueles em desenvolvimento. Coleman (2001) assinala que o envelhecimento populacional é uma das mais importantes transformações social e demográfica em curso nas sociedades humanas.

7 Segundo as hipóteses adotadas nas projeções, a taxa de fecundidade total (TFT) cairia a um patamar de 1,5 filho por mulher por volta de 2035, ficando constante até o horizonte da projeção no ano de 2060 (Gráfico 1). Já a esperança de vida ao nascer (E0), para ambos os sexos, seria de 81,2 anos, também no mesmo horizonte (Gráfico 2).

Gráfico 1 


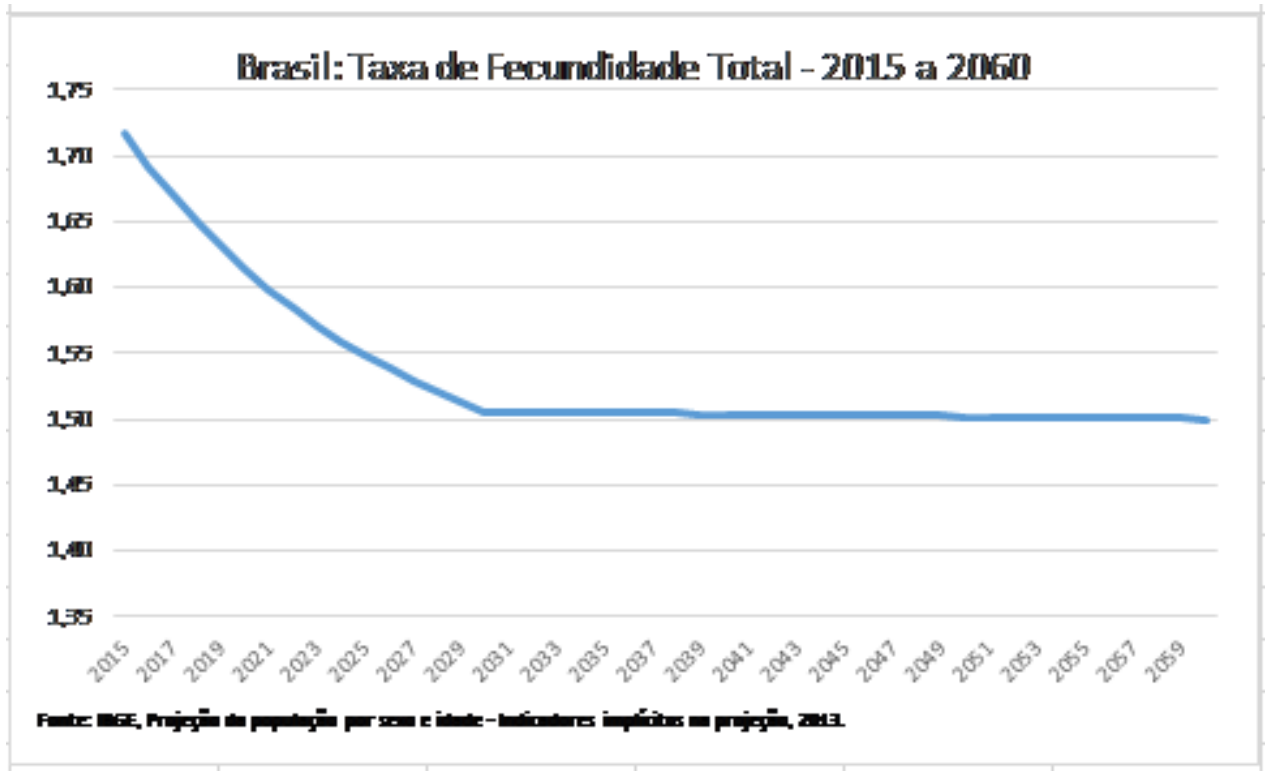

Fonte: IBGE, projeção da população por sexo e idade - indicadores implícitos na projeção

Gráfico 2

Brasil: esperança de vida ao nascer - 2015-2060

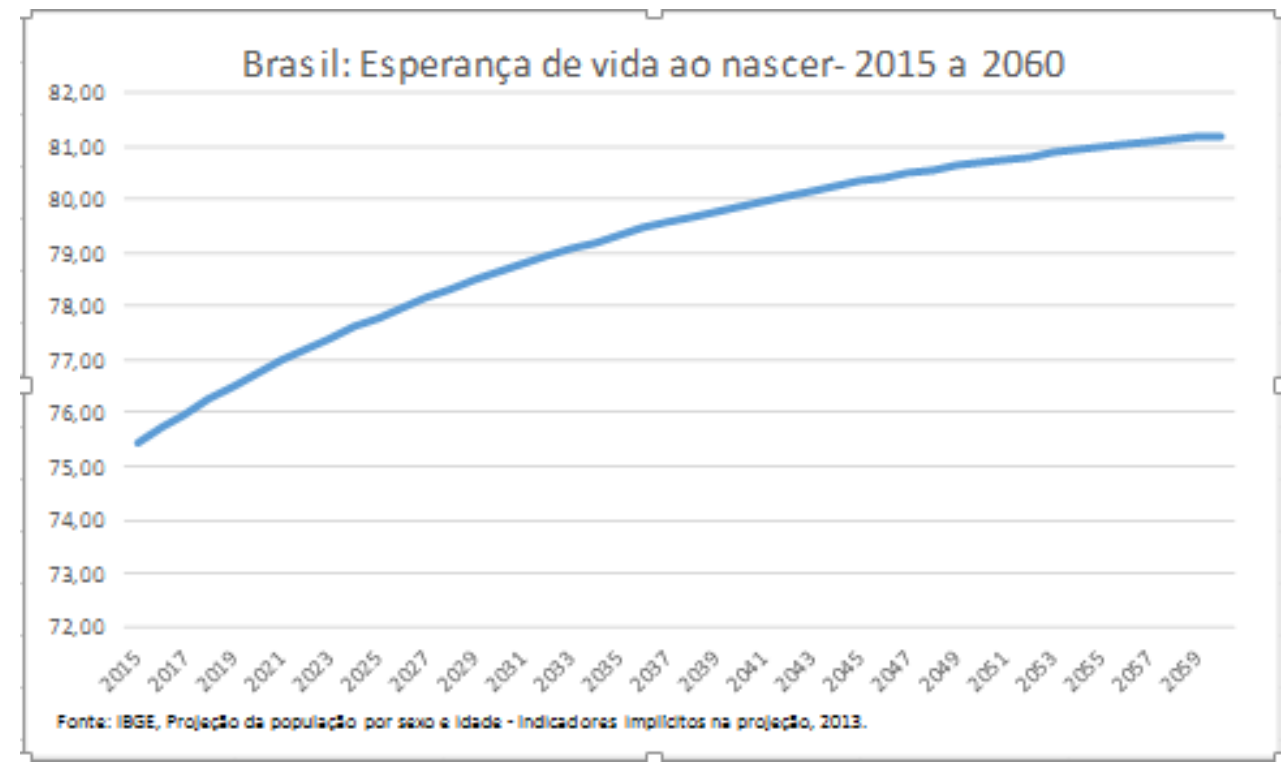

Fonte: IBGE, projeção da população por sexo e idade - indicadores implícitos na projeção, 2013

O comportamento da fecundidade e da mortalidade trará consequências não apenas no volume, mas também na estrutura da população. A trajetória de queda das TFTs, observada desde o ano de partida das projeções em 2000, já é suficiente para afetar o comportamento das taxas brutas de natalidade (TBN), implicando num volume menor de nascimentos. Por outro lado, o progressivo incremento na esperança de vida ocasiona o aumento no número de pessoas idosas, resultando num maior número de óbitos e na 
elevação das taxas brutas de mortalidade (TBM) que, após sofrer tendência de queda até o início dos anos 2010, passa a ter um ritmo continuado de crescimento até o horizonte das projeções (Gráfico 3).

Gráfico 3

Estimativas das taxas brutas de natalidade e mortalidade - Brasil 2010-2060

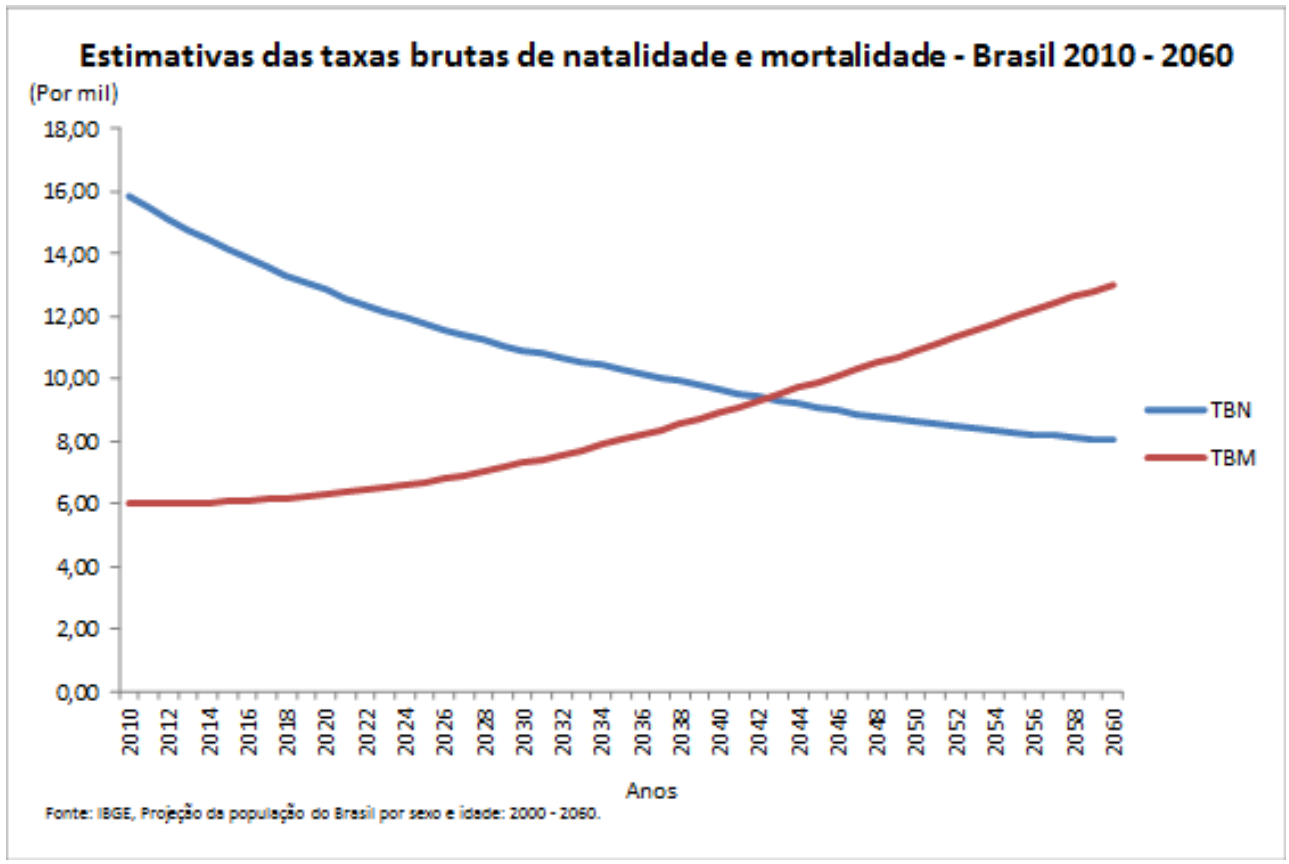

Fonte: IBGE, projeção da população do Brasil por sexo e idade, 2000-2060.

Essas tendências das taxas brutas de natalidade e mortalidade acarretarão, no início dos anos 2040, a redução no volume populacional do Brasil justamente no ponto onde se cruzam as linhas da TBN e TBM - como pode ser observado no Gráfico 3. Após alcançar um máximo de aproximadamente 228 milhões de habitantes, a população residente no Brasil passará a diminuir de tamanho. Isso até poderia não ser considerado ruim se fossem levados em conta os aspectos relacionados à diminuição da pressão sobre a produção e o consumo, bem como o reflexo positivo disso no ambiente. Mas esse cenário sugere que o país está diante de uma questão que diz respeito mais à qualidade do que à quantidade dessa população.

Cabe salientar que o ritmo dessas mudanças é distinto em cada uma das Regiões Geográficas do país, refletindo as assimetrias especiais do desenvolvimento econômico e social. Contudo, no horizonte das projeções, os indicadores de fecundidade e mortalidade convergirão com o Norte e Nordeste alcançando níveis de TFT e E0 bem próximos aos observados no Centro-Sul (Mapas 1 e 2). Todas as Unidades da Federação experimentarão taxas de fecundidade total abaixo do nível de reposição, sendo que nove delas abaixo de 1,5 filho por mulher. No que tange à esperança de vida ao nascer, em vinte e uma das UFs o indicador superará os 75 anos, sendo que em seis delas o valor será de no mínimo 80 anos, o que será bem superior ao esperado para a média mundial (UNITED NATIONS, 2015). 
Mapa 1

Taxa de fecundidade total segundo unidades da Federação - Brasil 2010 e 2030

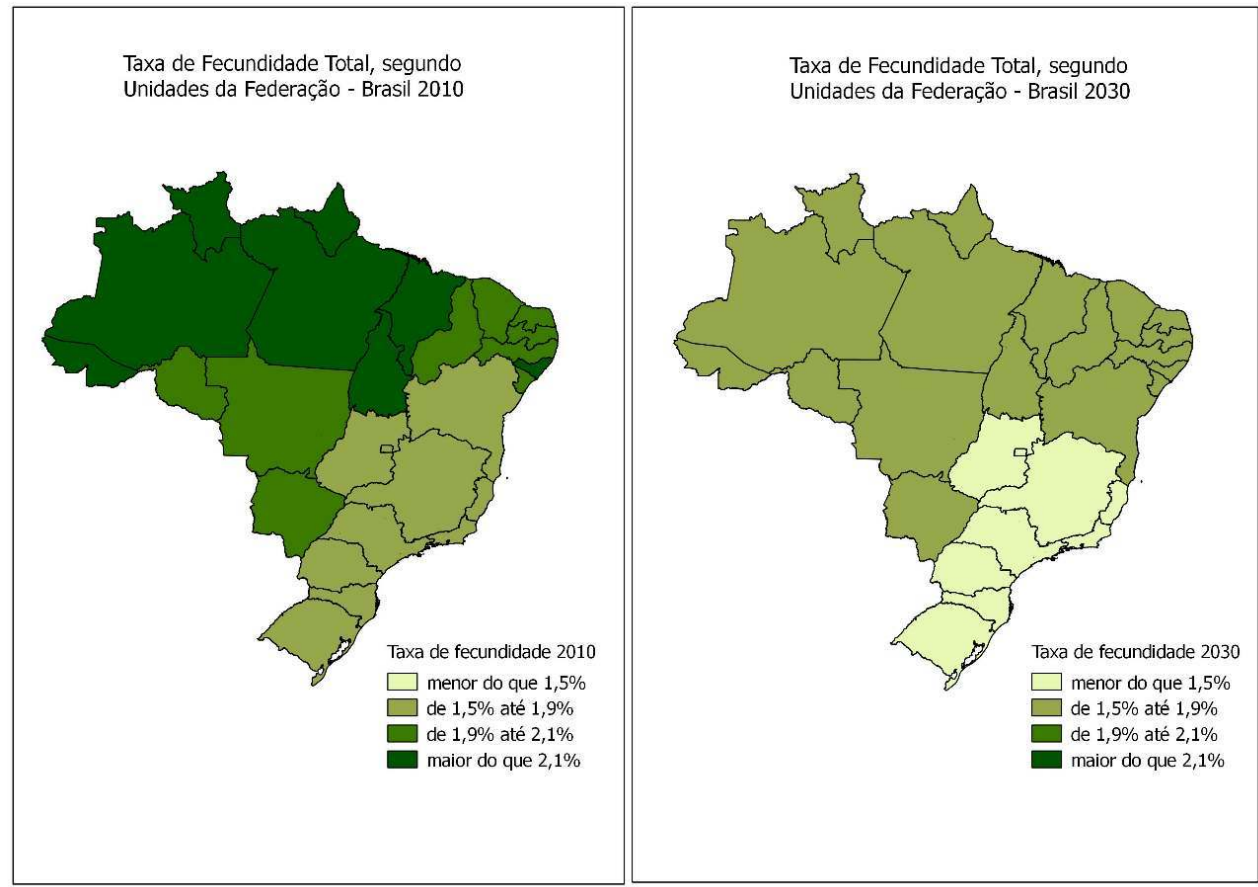

Fonte: IBGE, Projeção da População das Unidades da Federação por sexo e idade: 2000-2030

Mapa 2 
Esperança de vida ao nascer segundo unidades da Federação - Brasil 2010 e 2030

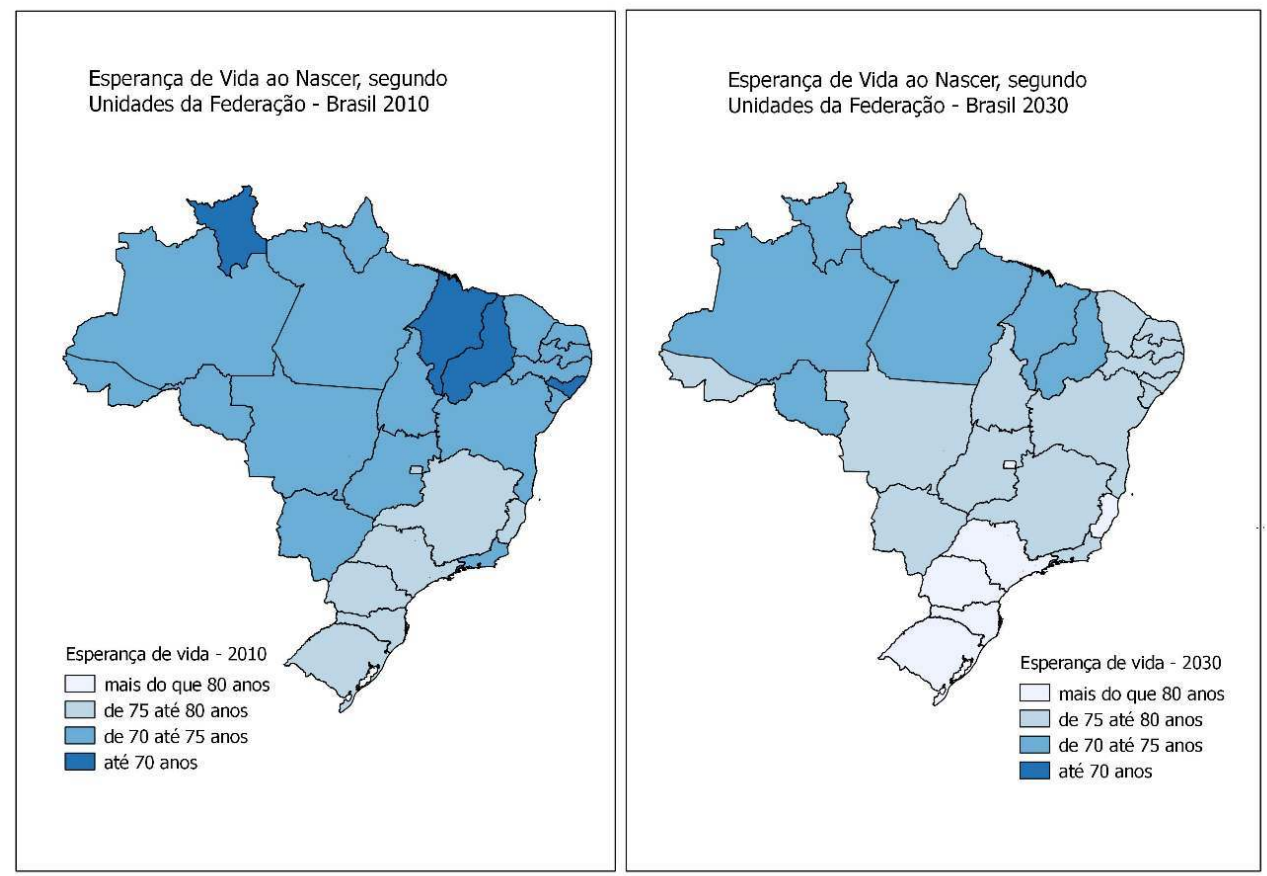

Fonte: IBGE, PROJEÇÃo dA POPULAÇÃo dAS UNIDADES DA FEDERAÇÃO POR SEXO E IDADE: 2000-2030.

11 As transformações na dinâmica demográfica não impactarão apenas o volume, mas também em mudanças na estrutura etária, com a redução no número de crianças e o aumento no segmento idoso. A população em idade ativa, igualmente, sofrerá os impactos dessa dinâmica tanto quantitativamente quanto qualitativamente.

12 As pirâmides etárias para os anos 2015 e 2060 apresentam a exata medida dessas mudanças a partir da completa inversão das figuras, sendo possível observar a concentração da população no grupo etário com 40 anos ou mais de idade (Gráficos 4 e 5).

Gráfico 4 
Brasil: Pirâmide Etária 2015

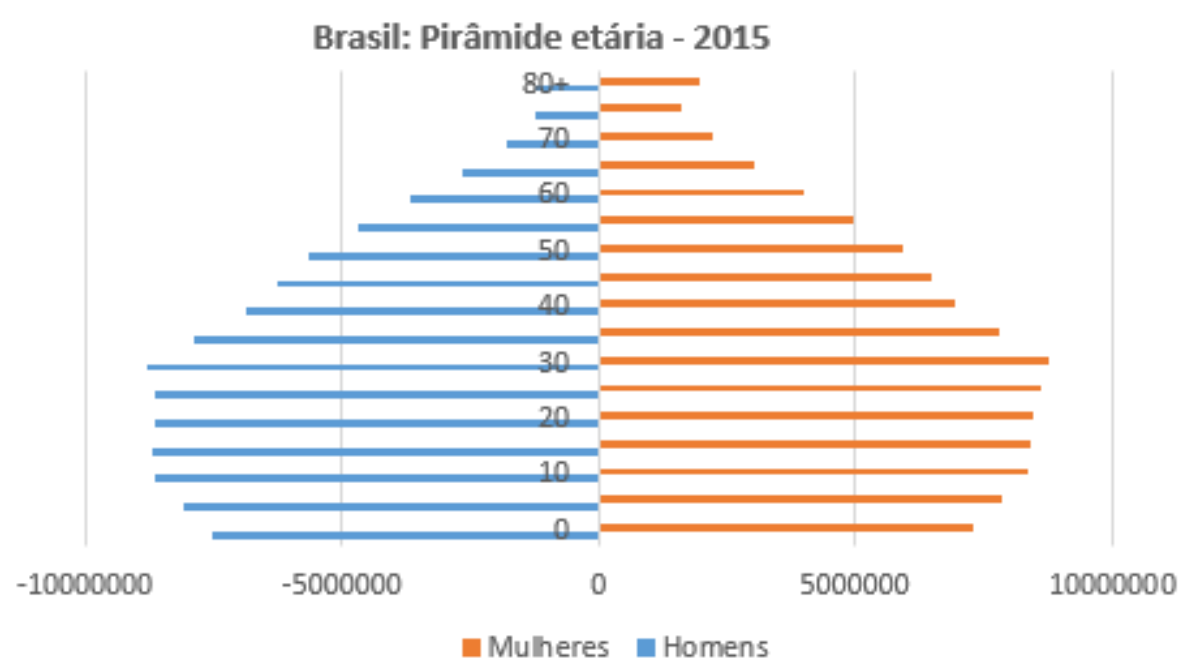

Fonte: IBGE, Projeção de população do Brasil por sexo e idade: 2000-2060.

Fonte: IBGE, Brasil, projeção da população por sexo e grupos de idade, 2000-2060.

Gráfico 5

Brasil: Pirâmide Etária 2060

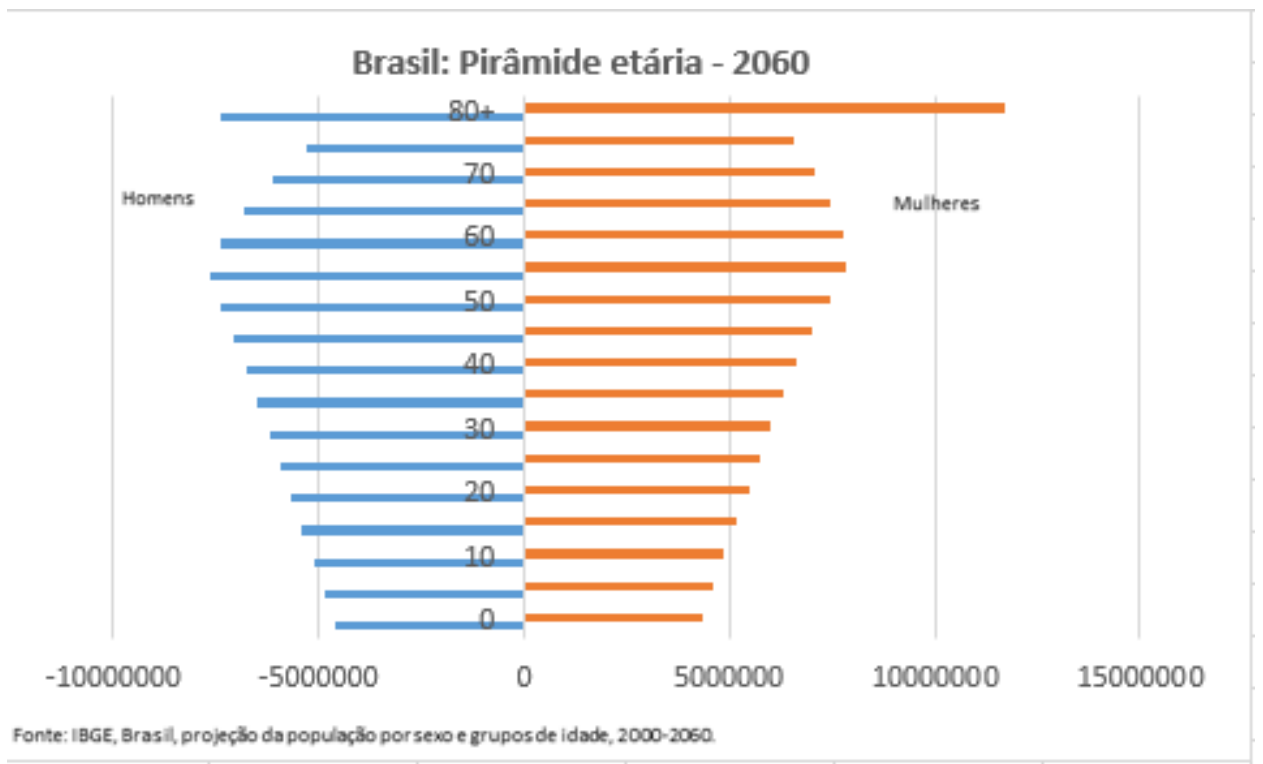

Fonte: IBGE, Brasil, projeção da população por sexo e grupos de idade, 2000-2060.

13 O exame das razões de dependência total de jovens e idosos e da taxa de suporte potencial é revelador do que se espera para o comportamento demográfico num futuro nem tão distante, dado que se trata dos próximos 45 anos (Tabela 1). 
Tabela $1^{1}$ : Brasil: Razões de dependências

\begin{tabular}{c|c|c|c|c|c}
\hline \multicolumn{6}{|c|}{ Tabela 1 } \\
\hline \multicolumn{7}{|c|}{ Brasil: Razões de dependências jovem, idoso e total, índice de } \\
\hline Ano & RDJ & RDI & RDT & IE & TSP \\
\hline \hline 2015 & 33,6 & 11,5 & 45,1 & 34,1 & 8,6 \\
2020 & 30,0 & 13,5 & 43,5 & 45,1 & 7,7 \\
2030 & 25,5 & 19,5 & 45,0 & 76,4 & 5,1 \\
2040 & 23,2 & 26,3 & 49,5 & 113,2 & 3,8 \\
2050 & 22,2 & 35,8 & 58,0 & 161,0 & 2,8 \\
2060 & 21,6 & 44,4 & 66,0 & 206,2 & 2,3 \\
\hline
\end{tabular}

Fonte: IBGE, Projeção da população por sexo e grupos de idade, 2000-2060.

Fonte: IBGE, projeção da população por sexo e grupos de idade, 2000-2060. 
objetivo é levantar, para debate e reflexão, alguns dos pontos considerados fundamentais, apontando aspectos do campo demográfico, social, econômico e político associados diretamente aos desafios colocados por esse fenômeno demográfico. Tendo em conta esses fatores, cabe a discussão da oportunidade da implementação de políticas populacionais, sejam as de estímulo à natalidade, sejam as que incentivem a migração ou a combinação de ambas. Por outro lado, face ao que será exposto a seguir, a elaboração de políticas que visem enfrentar os desafios demográficos não pode estar descolada de um projeto mais amplo de nação que vise alcançar o desenvolvimento econômico-social inclusivo de todos os segmentos da sociedade brasileira.

\section{O “bônus demográfico" não aproveitado}

19 Como já mencionado, o "bônus demográfico", que por volta do início dos anos 1980 começou a se processar com a redução da razão de dependência total, não foi ou não será aproveitado em sua plenitude, haja vista que nos próximos anos a "janela de oportunidades" se fechará.

20 A janela começou a se abrir justamente na década considerada como a "perdida" em função da estagnação pela qual atravessou o país. Em 1989, a nação observou, com a ascensão de Collor (1990-1992) ao poder, a instalação de políticas neoliberais que seguiam o receituário do Estado mínimo, jogando para o mercado tudo o que fosse relacionado ao acesso aos serviços básicos, como saúde, educação e proteção social. Após a queda de Collor, mergulhado em escândalos de corrupção e afundando o país numa inflação jamais vista, assume Itamar Franco (1992-1994), que fez um governo de transição voltado a preparar os fundamentos econômicos para debelar a inflação, o que seria alcançado no governo seguinte de Fernando Henrique Cardoso.

21 A gestão de Cardoso (1995-2002), deitado nos louros da derrubada da inflação, aprofundou os preceitos neoliberais, enxugando o Estado e entregando as empresas estatais num vergonhoso processo de privatização. Ao que tudo parece, a necessária presença da máquina pública para estimular os fundamentos necessários ao aproveitamento do bônus demográfico não se coadunava com a visão política desses governos.

Em seguida, o país passou a experimentar a Era Lula-Dilma. As esperanças se renovaram com a presença de governos tidos como de esquerda e progressistas. Nesse mesmo período, os debates sobre a "janela de oportunidades" e seus benefícios para o país ganham mais intensidade, ao menos na comunidade dos demógrafos. Contudo, o governo Lula (2003-2010), apesar de "surfar" em ondas muito favoráveis do ponto de vista da conjuntura econômica internacional, tampouco dotou o país das condições necessárias para gerar a poupança nacional ou dos seus cidadãos. A adoção de políticas focais, algumas delas necessárias e emergenciais, como os programas de transferência de rendas, não foi acompanhada de medidas que provocassem transformações estruturais nos campos econômico e social.

23 A gestão de Dilma Rousseff (2011-) tem se mostrado desastrosa em todos os sentidos. Após Lula ter enfrentado satisfatoriamente a crise econômica internacional de 2008, com o país apresentando resultados bastante positivos do seu produto interno bruto em 2010 e 2011, Rousseff, além de não corrigir os aspectos relacionados aos incentivos fiscais, trava o crescimento econômico, mergulhando o país numa crise econômica, social e política há muito tempo não vista. 
De 2011 a 2012, em iniciativa de audácia inesperada, os desenvolvimentistas invadiram a cidadela sagrada das decisões monetárias e avançaram aos saltos, pressionando instituições privadas para reduzirem os próprios ganhos, com o apoio das divisões pesadas dos bancos públicos e de ousada mudança nas regras da poupança. Quando a refrega parecia ganha, abrindo caminho para horizontes rooseveltianos, o poderoso Banco Central (BC) voltou a elevar a taxa Selic (abril de 2013) e, na prática, devolveu ao mercado financeiro controle sobre parte fundamental da política econômica. A decisão tornava manca a perspectiva de retomada do desenvolvimento nacional e paralisava o avanço progressista quando ele soava irresistível (SINGER, 2015, p 40).

Esse breve relato da relação das políticas econômicas e a correlata etapa do "bônus demográfico" revela que a questão populacional não fez parte da pauta de ações de nenhum dos governos contemporâneos à abertura da "janela de oportunidades". Quando eventualmente o tema surgia, ele sempre esteve associado à dimensão previdenciária, num debate enviesado que buscava jogar para os trabalhadores um problema de "déficit" até hoje não explicitado. Por outro lado, apesar de não constar da agenda governamental, o "bônus demográfico" poderia ter sido aproveitado, mesmo que não planejado, caso os modelos de desenvolvimento adotados fossem outros.

\section{Os fundamentos econômicos}

Para se elaborar políticas públicas que visem o enfrentamento das diversas dimensões associadas ao envelhecimento populacional, é necessário que os fundamentos econômicos sejam sólidos. A análise do padrão de reprodução do capital vigente nos países latinoamericanos sinaliza a inserção periférica do Brasil no sistema capitalista global, algo que inibe e restringe o desenvolvimento econômico do país.

Marini (2012) e Osório (2012a, 2012b) já chamavam atenção para o papel reservado pelos países capitalistas centrais aos países periféricos. Nesse contexto de reconfiguração do padrão de reprodução do capital, os países em desenvolvimento ficariam responsáveis pelas etapas inferiores do processo de produção, a complementariedade da produção mais geral e a exportação da especialização produtiva. Aos países centrais caberiam as etapas superiores e o controle tecnológico e financeiro, caracterizado:

“pelo regresso a produções seletivas, seja bens de consumo e/ou primários, seja de relocalização de segmentos produtivos, novas organizações da produção, em geral qualificadas como toyotismo, flexibilidade laboral e precariedade, economias voltadas para a exportação..." (OSÓRIO, 2012a, p.85).

Para Oliveira,

"nesse novo padrão exportador teriam destaque os bens agromineiros e alguns bens secundários, sejam os de produção local, sejam os de montadoras. Enfim, a especialização produtiva estaria articulada, sobretudo, em eixos como a produção de petróleo e derivados, extração e processamento de minerais ferrosos, soja, montadoras de automóveis e produtos eletrônicos, serviços de call center" (OLIVEIRA, 2014, p.35).

Parece óbvio que, nos governos recentes, seja os de inspiração neoliberal, seja nos que se apresentaram com uma proposta mais progressista, a opção do país foi por uma inserção subordinada no circuito global do capital. Não bastasse essa dependência estrutural da economia brasileira, o país no momento atravessa uma profunda crise econômica, reflexo dessa opção e fruto principalmente da queda dos preços das commodities. Essa crise inibe as iniciativas necessárias ao aproveitamento do que resta do "bônus demográfico", bem 
como da implementação das medidas preventivas ao envelhecimento populacional. Deste modo, para enfrentar a redução da mão-de-obra disponível e gerar recursos para tratar das questões associadas à maior longevidade da sociedade brasileira, não há outra saída que não seja investir em atividades econômicas intensivas em conhecimento e tecnologia que proporcionem o aumento nos índices de produtividade da força de trabalho, o que implica enfrentar os gargalos da educação.

\section{Gargalos da educação}

29 Como demonstrado na Tabela 1 , o volume de crianças e adolescentes já vem apresentando tendência de queda nos últimos anos, como reflexo mais imediato da redução dos níveis da fecundidade e o efeito disso nas taxas de natalidade. Isso resulta numa menor pressão no ensino fundamental e médio, algo que seria extremamente positivo, pois implicaria num menor dispêndio de recursos humanos e financeiros.

30 Um olhar através das últimas duas décadas revela que houve aumento no número de matrículas no ensino fundamental e, mais recentemente, nos governos Lula-Dilma, a expansão do ensino superior com a construção de vários equipamentos públicos e a parceria com a iniciativa privada através de programas como o Universidade para Todos (PROUNI) e a ampliação do financiamento via o Fundo de Financiamento Estudantil (FIES) 3. Contudo, outros fatores negativos se fizeram presentes: i) quase não se notou avanços na oferta de creches, o que inibe a liberação da força de trabalho feminina, que no Brasil apresenta baixa taxa de atividade laboral; ii) a evasão no ensino médio supera $20 \%$; iii) o ensino superior, particularmente o privado, se massificou em detrimento da qualidade, problema que também afeta os ensinos fundamental e médio.

Fica evidente que faltou um plano nacional de educação. O relatório da ONG Todos Pela Educação divulgado em 2015 aponta que das cinco metas estabelecidas o país não cumpriu quatro delas (TPE, 2015). Fagnani (2014) assinala que o país convive com profundas ausências no campo educacional e associa esse anacronismo à persistente desigualdade na sociedade brasileira e aos aspectos endógenos do sistema de ensino. Aponta ser necessária a criação de uma agenda nacional, na perspectiva do desenvolvimento, que contemple os seguintes pontos: i) reformas estruturais para ampliar o financiamento; ii) fortalecer o pacto federativo; iii) "desmercantilizar" a oferta de serviços; e iv) promover a eficiência da gestão pública.

32 Em resumo, na principal matriz de insumos para a formação de uma força de trabalho mais qualificada e que proporcione os requisitos para gerar as inovações tecnológicas, de modo a fazer frente ao necessário aumento de produtividade, o país falha. É imperioso que se invista na melhoria da gestão e da qualidade do sistema de ensino no país, condição para que seja alcançado o patamar no qual as atividades econômicas sejam intensivas em conhecimento e proporcionem o aumento da produtividade da nossa força de trabalho, amenizando assim a falta de braços e o envelhecimento da população economicamente ativa - de modo a pavimentar o caminho que levará ao desenvolvimento econômico e social menos desigual. 


\section{A proteção social: saúde, previdência e atenção à população idosa}

33 O processo de envelhecimento populacional acarretará fortes impactos nas áreas da saúde, previdência social e cuidado com a pessoa idosa. Nos dois primeiros tópicos, via de regra, quando se aborda o tema é pela perspectiva do catastrofismo, realçando a dimensão dos custos para enfrentar as enfermidades caraterísticas das idades mais avançadas e o "rombo" nas contas da previdência. Em relação aos cuidados, proteção, envelhecimento saudável e integração dos idosos, quase nada é tratado. A seguir serão apresentados alguns contrapontos à visão na qual, frente à "hecatombe", a saída é aumentar impostos, reformar a previdência pública e mercantilizar a previdência social e a saúde.

\section{A saúde}

Em relação à saúde, o sucateamento do Sistema Único de Saúde (SUS), que não se tornou totalmente universal e ainda apresenta vazios geográficos na oferta dos serviços de média e alta complexidades, não anima enfrentar as morbidades que se farão ainda mais presentes num cenário de aumento da população idosa. A área da saúde necessariamente precisa reestruturar fontes de financiamento e processos de gestão para confrontar de forma adequada as questões associadas à maior longevidade da população e ao funcionamento do sistema como um todo.

Com o processo de envelhecimento, a incidência de doenças, entre outras, cardiorrespiratórias, neoplasias, gripes e maior frequência ambulatorial, associados a períodos mais longos de internação, causarão fortes impactos nos gastos com saúde, tornando-os cada vez maiores ao longo do tempo. Essa é uma constatação nos dias atuais em boa parte do mundo.

Lobo (2014) assinala que parcela importante dos custos no sistema de saúde estão ligados a estilos do exercício da medicina, especialização excessiva, intensidade de recursos por ato médico, inovações tecnológicas (equipamentos e medicamentos), interesses industriais, além da inflação que sugere ser mais elevada na área de saúde. Quando observa a relação dos gastos de saúde entre os grupos de idade, constata que na Espanha o atendimento às pessoas com mais de 64 anos e três vezes maior do que com as que possuem entre $34 \mathrm{e} 44$ anos de idade.

37 Frente a essa realidade, o autor, buscando entender os impactos crescentes dos gastos, identificou que parcela expressiva estava vinculada às inovações tecnológicas e aos interesses da indústria, que cobra cada vez mais por cada novo medicamento ou equipamento colocado no mercado. A contribuição do envelhecimento em si para o crescimento dos gastos tem sido moderada, de onde se depreende que o aspecto demográfico não é a principal ameaça à sustentabilidade financeira dos sistemas públicos de saúde.

Qual seriam os pontos centrais dessa discussão? O primeiro, a quebra de patentes, de modo a tornar menos onerosas as novidades na área médica. 0 segundo trata da questão do financiamento das pesquisas tecnológicas nas indústrias farmacêuticas e de equipamentos médicos, estimulando que descobertas sigam surgindo, de forma que essas 
inovações sejam apropriadas socialmente a preços justos e acessíveis, tudo isso num contexto de capitalismo cada vez mais globalizado.

Não é um desafio nada simples, dado que a concorrência é inerente ao modo de produção capitalista, como ensinou Marx. Idealmente, essa discussão deveria ser travada na esfera dos organismos internacionais, podendo ser criado um fundo para financiar as pesquisas, de modo que os benefícios dos achados atingissem todos os países. Os interesses privados em algo de tamanha importância não poderia se sobrepor aos interesses coletivos voltados para garantia do acesso a medicamentos e equipamentos de saúde. Iniciativas unilaterais que visem quebrar patentes deveriam ser tomadas apenas como medida extrema, como forma de viabilizar o acesso a essas inovações.

\section{A previdência social}

40 O debate sobre a questão previdenciária é o que tem maior visibilidade. Normalmente, travado de forma enviesada, dado que nem todos os elementos que envolvem a questão são colocados e sempre partem do pressuposto da existência de déficit, que só se agravará com a maior longevidade da população e provocará o colapso das contas públicas. As saídas apontadas por esse enfoque alarmista são: o aumento da contribuição do trabalhador, a elevação da idade para aposentadoria e estímulos para que se recorra à previdência privada, o que fica claro com o teto dos benefícios e os limites impostos aos empregados públicos que ingressaram após 2010, que não fazem jus à aposentadoria com vencimentos integrais.

41 Gentil (2007) apresenta uma outra abordagem para o tema, contextualizando que o pensamento neoliberal, mundialmente hegemônico a partir dos anos 1980, passou a enxergar o sistema previdenciário público pela ótica da crise. Como esse pensamento também teve por objetivo atacar as instituições do estado de bem-estar social, a solução do problema recairia nas costas dos trabalhadores.

42 A autora destaca que os números que apontam para uma magnitude assombrosa do déficit, via de regra, partem de uma metodologia que não é adequada para avaliar o desempenho do sistema previdenciário. Esses cálculos para chegar a arrecadação líquida negativa levam em conta receita de contribuição do INSS, mais outros recebimentos próprios, menos ressarcimentos, restituições de arrecadação e transferências a terceiros. Essa arrecadação líquida, subtraídos os gastos com benefícios do Regime Geral de Previdência Social (RGPS), resultaria no saldo previdenciário. O correto, ainda segundo a autora, seria levar em consideração o que prevê a Constituição Federal de 1988 em seus artigos 194 e 195, que estabelecem um sistema integrado de previdência social envolvendo saúde, assistência social e previdência, bem como define as fontes de financiamento. Desse modo, seriam considerados no cálculo as contribuições de empregadores e empregados; a Contribuição para Financiamento da Seguridade Social (COFINS), inclusive sobre importações; a Contribuição sobre o Lucro Líquido (CSLL); e a receita de concursos de prognósticos. Além disso, a referida Constituição diz que a Seguridade Social também será financiada com recursos oriundos do orçamento da União.

Além de evitar que o peso pela sustentação do sistema recaísse, principalmente, nos ombros dos trabalhadores, a solução alcançada evita que em momentos de crise econômica mais prolongada, com reflexos no nível de produção e no mercado de trabalho, sobretudo com o aumento do desemprego, a arrecadação do sistema seja afetada (GENTIL, 2007). 
Esse contraponto às posições mais alarmistas indica que a discussão sobre a questão previdenciária tem que pacificar o entendimento do que está prescrito na Constituição Federal, sem o quê qualquer política pode estar comprometida. $O$ debate vai aclarar posições favoráveis à manutenção do pacto social obtido quando da elaboração da Constituição Federal de 1988 e aqueles que querem romper com esse acordo.

\section{Atenção e cuidado}

Além das dimensões da saúde e da previdência social, a agenda sobre a atenção, proteção e cuidado da pessoa idosa deve estar na ordem do dia. 0 envelhecimento saudável passa pela plena integração desse segmento na vida social, onde devem ser garantidos, entre outros direitos, mobilidade e acessibilidade, atividades físicas, culturais e sociais e equipamentos públicos de atenção e cuidado. Uma outra dimensão muito relevante diz respeito à formação de profissionais que serão cada dia mais demandados nas atividades de cuidado, sejam esses nas áreas médicas e fisioterápicas ou no cuidado direto, setor muito carente de preparo adequado.

\section{As políticas populacionais}

Do ponto de vista estritamente demográfico, soluções para a redução dos volumes populacionais e para o envelhecimento devem vir do aumento dos níveis de fecundidade e da atração migratória. Por tudo que foi assinalado acima, no que diz respeito às condições estruturais no país, observar a inércia demográfica sem que sejam implementadas políticas públicas que afrontem as questões populacionais pode implicar na reprodução e até no aprofundamento das desigualdades:

A capacidade de a transição demográfica potencializar as transferências intergeracionais de recursos está intimamente associada à implementação de políticas que potencializem as transferências sociais desses mesmos recursos (Brito, 2008, p.5)

47 Bacci (2012) destaca que as soluções para o envelhecimento populacional são buscadas por intermédio de duas vias básicas: i) reprodução biológica, onde se procura estimular a natalidade visando, sobretudo, manter intactas culturas e tradições e seus próprios recursos humanos, sendo o exemplo mais clássico o Japão; e ii) reprodução social, operando através do incentivo à imigração repor a população em idade de trabalho, de forma a assegurar o equilíbrio econômico e social e assumindo que esse processo implica numa maior integração cultural. Exemplos: Canadá e Austrália.

No Brasil, apesar do não reconhecimento à nova realidade migratória, onde a presença do estrangeiro, embora não extremamente volumosa, é bem significativa, faz com que os imigrantes, sobretudo os mais recentes, tenham profundas dificuldades em acessar os serviços públicos. Todavia, dada a constituição histórica marcada pela mescla de culturas, fruto dos processos imigratórios, e onde as manifestações racistas e preconceituosas contra os imigrantes são residuais, é perfeitamente possível a combinação das duas vias apontadas pelo autor, sobretudo porque as evidências empíricas sinalizam que nos países que procuram solucionar a questão do envelhecimento populacional por uma via ou por outra o objetivo não foi plenamente alcançado. Além disso, não se pode perder de vista uma outra dimensão fundamental que é aumentar a produtividade futura da força de trabalho. 
49 No caso brasileiro, a implementação dessas iniciativas esbarra em dificuldades de caráter estrutural que, para serem bem-sucedidas, vão requerer a superação de alguns obstáculos.

\section{Incentivo à natalidade}

O caminho das políticas pró-natalistas é mais longo, não só pelo tempo para surtir o resultado demográfico esperado, dado que as iniciativas tardam ao menos vinte anos para se efetivarem, como também pela inexistência de uma série de medidas nas áreas de gênero e saúde sexual e reprodutiva, sem as quais dificilmente o incentivo à natalidade alcançaria bom termo. De todo modo, as possíveis políticas devem ser discutidas com a sociedade e não devem ter caráter punitivo ou restritivo. Isto quer dizer que a decisão de aumentar os níveis da fecundidade e as respectivas medidas de incentivos e seus alcances devem ser decididos socialmente.

Neste campo, o que se coloca para o país é a superação de entraves na atenção à mulher, no tocante à saúde sexual e reprodutiva, reprodução assistida, programas de planejamento familiar, infraestrutura de cuidado e atenção às crianças, maior equidade nas relações de gênero, sobretudo nas que se dão na esfera do trabalho. Questões como diferenças salariais, opção por qual cônjuge ou membro da família se encarregará do cuidado da criança nos primeiros meses de vida etc., devem ser equacionadas. Os modelos existentes nos países que incentivam à natalidade mostram que, além de aportar recursos financeiros às famílias, em maior ou menor medida também ensaiou-se resolver as questões apontadas acima.

52 Avançar nesse tipo de política requer que o país enfrente um desafio maior que ampliar sua capacidade de aportar com recursos humanos e materiais. Demandará uma mudança cultural privada e pública. Sem isso, o grau de resposta às políticas de estímulo à natalidade tende a ser muito baixo.

\section{Implementação de políticas de atração migratória}

No campo da migração as coisas não são menos complicadas, a começar pelo estatuto jurídico vigente no país, estabelecido no período de exceção e baseado na segurança nacional, que enxerga o estrangeiro como ameaça à paz interna. Para que as políticas de atração migratória tenham algum sucesso é preciso superar essas restrições legais que, por exemplo, estabelecem que o estrangeiro só pode trabalhar no território nacional a partir da demanda da empresa que deseja empregá-lo ou trazê-lo para o país, o que limita muitíssimo a atração da força de trabalho migrante.

54 No momento, a proposta de uma nova lei migratória encontra-se tramitando no Congresso Nacional. As perspectivas são as de que se consiga avançar para um enfoque mais humanista no arcabouço legal, assegurando as garantias dos direitos dos migrantes, criando as condições para plena integração dos estrangeiros na sociedade brasileira e combatendo qualquer tipo de manifestação preconceituosa, racista ou xenófoba.

55 Contudo, mesmo nessa perspectiva, visões antagônicas se colocam em disputa: de um lado, os que enxergam na imigração uma saída meramente econômica e, desse modo, o desejável é que sejam atraídos apenas os trabalhadores qualificados. De outro lado, os que percebem a migração como direito à livre circulação e que a todo indivíduo, 
independentemente de sua nacionalidade, credo, ocupação, orientação sexual, devem ser asseguradas garantias iguais aos nacionais do país de acolhimento.

É impensável que se implemente políticas de atração migratória sem que sejam levados em consideração as dimensões do tripé regulação, integração e cooperação internacional, além de estarem asseguradas condições mínimas à população estrangeira.

“... i) pensar numa regulação de entrada e permanência onde o estrangeiro não seja visto como ameaça, assegurando o acesso ao território nacional a pessoa que não tenha sido condenada ou praticado crimes contra a ordem constitucional e o Estado Democrático, contra a humanidade, de guerra ou de genocídio; ii) envidar esforços no sentido de estabelecer e ampliar a cooperação internacional, tanto no que se refere às migrações, como o acolhimento humanitário, de refugiados e de asilados; e iii) apostar na plena integração do imigrante, passando, entre outros fatores, pela garantia ao trabalho digno, reconhecimento à qualificação anterior, acesso aos serviços de saúde, educação e previdência social, infraestrutura adequada de habitação, saneamento básico, transporte, segurança, direito ao voto e a não discriminação. Devendo-se destacar também a importância do local de moradia e da vizinhança como espaços de integração." (OLIVEIRA, 2015, p. 273.)

\section{Dimensões da política: "a emergência do conservadorismo"}

57 Todos os aspectos estruturais apontados acima não podem ser enfrentados sem que sejam revistas e aplicadas as políticas econômicas, sociais e populacionais. Face às várias dimensões envolvidas, é pouco provável que avanços significativos sejam alcançados sem que tenha claro qual o projeto de nação desejado.

58 Nos últimos anos, o mundo tem assistido o avanço de uma onda conservadora em países da Europa e da América Latina, com poucas exceções sendo observadas (Grécia, Espanha, Áustria e Uruguai). No que concerne às migrações, esses setores conservadores tendem a ser preconceituosos, racistas e, em casos extremos, xenófobos.

59 No Brasil, o desgaste dos setores progressistas, em função da atual crise política, econômica e ética, pode abrir caminho para que as forças conservadoras assumam a hegemonia política no país. Mesmo fora do governo, esses setores pressionam para rever o pacto social estabelecido quando da elaboração da Constituição Federal de 1988, querendo romper, principalmente, com os pontos ligados à Seguridade Social. Além disso, no campo da economia, são propostas políticas cada vez mais restritivas e que atentam contra os direitos dos trabalhadores.

60 Para fazer frente aos desafios colocados pelo processo de envelhecimento populacional, ao contrário de retrocessos e medidas focais, o país precisará de políticas universais que rompa com os limites estruturais da distribuição de renda, nas relações trabalhistas, financiamento da proteção social e nas desigualdades no acesso a bens e serviços (FPA, 2013).

\section{Considerações finais}

61 O processo de envelhecimento populacional é um fenômeno inexorável, o qual requer a consciência da sociedade brasileira não só para sua iminente ocorrência, mas, sobretudo, para os impactos que acarretará no desenvolvimento econômico e social futuro do país. As evidências empíricas, vindas dos países que se encontram numa etapa mais avançada da transição demográfica, permitem concluir que seja pela via da reprodução biológica, 
seja pela via da reprodução social, ainda não foi alcançada uma solução completa para a questão. Nem as políticas de incentivo à natalidade lograram levar a fecundidade a níveis superiores ao de reposição (2,1 filhos por mulher), nem as políticas de estímulo a atração migratória conseguiram repor integralmente a população em idade ativa. Contudo, conseguiram mitigar os efeitos da maior longevidade populacional e redução dos seus volumes.

62 No Brasil, que sequer experimentou o Estado de Bem-estar Social, os desafios são bem maiores e estão para além do aspecto demográfico. o que o texto tentou demonstrar é que essa questão não pode ser enfrentada de forma isolada das demais: daí a necessidade de um amplo debate na sociedade brasileira que envolva as agências governamentais.

Foram apontados os gargalos em função do não-aproveitamento da "janela de oportunidades", dos problemas estruturais na economia, educação, seguridade social e na política. Dado que a poupança social não foi gerada com o aproveitamento do "bônus demográfico", será ainda mais necessário definir as fontes e os mecanismos de financiamento para a saúde, previdência social pública e os cuidados junto à população idosa. Esse movimento deverá estar diretamente ligado às medidas que promovam o desenvolvimento econômico competitivo, que, por sua vez, passa por gerar os mecanismos que assegurem uma educação de qualidade e uma inserção no circuito internacional do capital que não seja subordinada.

Com uma sociedade mais bem formada, pode-se avançar em atividades intensivas em conhecimento e aumentar a produtividade da força de trabalho, amenizando os reflexos da redução da população em idade ativa e o envelhecimento populacional. Complementarmente, políticas de incentivo à natalidade e estímulo à atração migratória poderiam ser implementadas, uma vez superados os problemas de ordem econômica, social, cultural e política. Nessa última dimensão, o confronto de ideias com os setores conservadores, que vêm ganhando força ultimamente, é inevitável. Os avanços obtidos com a Constituição Cidadã de 1988 estão ameaçados. Ou caminha-se para um modelo baseado em políticas públicas universais ou corre-se o risco de que, nesse processo de transição demográfica, sejam reproduzidas as desigualdades e aumente a pobreza.

\section{BIBLIOGRAFIA}

BACCI, Livi M. Breve historia de las migraciones. Traducción: Marco Aurelio

Galmarini. Madrid: Alianza Editorial, 2012.

BRITO, F. A transição demográfica e desigualdades sociais no Brasil. Revista Brasileira de Estudos de População, v. 25, n. 1, p. 5-26, 2008.

CEPAL - Guía operacional para la implementación y el seguimiento del Consenso de Montevideo sobre Población y Desarrollo. Segunda Reunión de la Conferencia Regional sobre Población y Desarrollo de América Latina y el Caribe. Santiago de Chile: CELADE, noviembre de 2014. 
COLEMAN, D. A. Replacement migration, or why everyone is going to have to live in Korea: a fable for our times from the United Nations. Philosophical Transactions of the Royal Society of London B: Biological Sciences 357.1420 583-598, 2001.

FAGNANI, Eduardo Além da agenda endógena da educação: Propostas para a construção coletiva de um projeto de desenvolvimento. Revista Educação \& Sociedade., Campinas: Centro de Estudos de Educação e Sociedade, v. 35, nº. 129, out.-dez., 2014, p. 999-1026.

FPA Políticas sociais, desenvolvimento e cidadania. Ana Fonseca e Eduardo Fagnani (orgs.). São Paulo: Editora Fundação Perseu Abramo, 2013.

GENTIL, Denise L. A falsa crise do Sistema de Seguridade Social no Brasil: uma análise financeira do período 1990-2005. Congresso Trabalhista Brasileiro. Brasília: 7 a 11 de fevereiro de 2007.

IBGE, Projeção da população do Brasil por sexo e idade:2000-2060, Revisão 2013. Disponível em: http://ibge.gov.br/home/estatistica/populacao/projecao_da_populacao/2013/default_tab.shtm. Acessado em: 27/03/2016, às 10:01.

LOBO, Félix El envejecimiento y la economía. Ciclo de Conferencias Envejecimiento, Sociedad y Salud. Madrid: Fundación Ramón Areces, 2014

MARINI, Ruy Mauro Subdesenvolvimento e Revolução. Florianópolis: Editora Insular, 2012. 272 p. (Coleção Pátria Grande: 1$)$.

OLIVEIRA, Antônio Tadeu R. de Políticas migratórias e migrações internacionais no Brasil. Orgs CAVALCANTI, Leonardo et al, Cadernos OBMigra. Brasília: Editora Especial, vol 1. nº 3, 2015, p. 252-278.

OLIVEIRA, Antônio Tadeu R. de Buscando apreender o comportamento recente das migrações internas. Revita Eletrônica Emetropolis. Rio de Janeiro: Observatório das Metrópoles, no 19, ano 5, dezembro de 2014. p.27-37.

OSÓRIO, Jaime Padrão de reprodução do capital: uma proposta teórica. In: Ferreira, Carla et al. (orgs.) Padrão de reprodução do capital: contribuições da teoria marxista da dependência. São Paulo, SP: Boitempo, 2012, p. 37-86.

OSÓRIO, Jaime América Latina: um novo padrão exportador de especialização produtiva - estudo de cinco economias da região. In: Ferreira, Carla et al. (orgs.) Padrão de reprodução do capital: contribuições da teoria marxista da dependência. São Paulo, SP: Boitempo, 2012, p. 103-133.

SINGER, André Cutucando onças com vara curta: 0 ensaio desenvolvimentista no primeiro mandato Dilma Rousseff (2011-2014). Novos Estudos. São Paulo: CEBRAP, no 102, julho de 2015, p 39-67.

TPE - Indicadores para educação 2015. Disponível em: http://www.todospelaeducacao.org.br/ indicadores-da-educacao/5-metas?task=indicador_educacao\&id_indicador=9\#filtros. Acessado em 29/03/2016, às 17:38h.

UNITED NATIONS, World Population Prospects: The 2015 Revision. New York: Population Division, Department of Economic and Social Affairs, 2015. Disponível em: http://esa.un.org/ unpd/wpp/Download/Standard/Mortality/. Acesso em 26/03/2016, às 15:25h. 


\section{NOTAS}

1. A razão de dependência total (RDT) é a relação entre os segmentos etários não ativos ( 0 a 14 e 65 anos ou mais) e a população em idades potencialmente ativas (15 a 64 anos); a razão de dependência de jovens (RDJ) é a relação entre o segmento etário de 0 a 14 e a população em idades potencialmente ativas (15 a 64 anos); a razão de dependência de idosos (RDI) é a relação entre o segmento etário 65 anos ou mais e a população em idades potencialmente ativas (15 a 64 anos); o índice de envelhecimento é a relação entre o segmento etário 65 anos ou mais e o grupo etário de 0 a 14; e a taxa de suporte potencial é a relação entre população em idades potencialmente ativas ( 15 a 64 anos) e o segmento etário 65 anos ou mais.

2. População economicamente ativa com idade entre 50 a 59 anos de idade.

3. Prouni - programa do Ministério da Educação, criado pela Lei no 11.096 , de 13 de janeiro de 2005, que concede bolsas de estudo integrais e parciais de $50 \%$ em instituições privadas de educação superior, em cursos de graduação e sequenciais de formação específica, a estudantes brasileiros sem diploma de nível superior. FIES é um programa do Ministério da Educação destinado a financiar a graduação na educação superior de estudantes matriculados em cursos superiores não gratuitas na forma da Lei 10.260/2001. Podem recorrer ao financiamento os estudantes matriculados em cursos superiores que tenham avaliação positiva nos processos conduzidos pelo Ministério da Educação.

\section{RESUMOS}

$\mathrm{O}$ artigo tem por objetivo estimular um amplo debate na sociedade sobre como enfrentar os desafios do envelhecimento populacional, sugerindo para tanto a adoção de um modelo inclusivo de desenvolvimento econômico e social que invista em educação, saúde e na previdência social pública, com a devida atenção à população idosa. Aponta-se também a relevância de políticas populacionais de incentivo à natalidade e de estímulo à imigração internacional. Tal agenda opõe-se frontalmente à inspiração neoliberal propagada pelos setores políticos conservadores.

Promoting a broad discussion within our society about how to face the challenges of population ageing is intended, suggesting for such the adoption of an inclusive economic and social development model that invests in education, health and social security, with proper attention to elderly population. The relevance of public policies that encourage birth rate's increase and international immigration are highlighted. Such agenda directly opposes to the neoliberal inspiration propagated by the conservative political sector.

Le but de cet article est de stimuler un large débat dans la société brésilienne à propos des défis $\mathrm{du}$ vieillissement démographique. Pour les confronter, il faut adopter un modèle de développement dont l'inclusion économique et sociale, l'éducation, la santé, l'attention aux personnes âgées et l'assurance sociale publique soient préservés. On souligne aussi l'importance des politiques d'encouragement à la natalité et à l'immigration internationale. Ce plan se bat contre le néoliberalisme propagé par les secteurs politiques conservateurs. 
El articulo tiene por objetivo estimular en la sociedad un debate amplio sobre cómo enfrentar los desafíos del envejecimiento de la población, sugiriendo la adopción de un modelo inclusivo de desarrollo económico y social que invierta en educación, salud y seguridad social, con la debida atención para la población adulta de la tercera edad. Igualmente se destaca la importancia de las políticas poblacionales de incentivo a la natalidad y de estímulo a la migración internacional. Esta agenda se encuentra en oposición directa con la aspiración neoliberal propagada por los sectores políticos conservadores.

\section{ÍNDICE}

Palabras claves: Envejecimiento de la población, transición demográfica, políticas públicas, desarrollo socioeconómico, Brasil.

Keywords: Population ageing, demographic transition, public policies, social and economic development, Brazil.

Mots-clés: viellissement démographique, transition démographique, politiques publiques, développement économique et social, Brésil

Palavras-chave: envelhecimento populacional, transição demográfica, políticas públicas, desenvolvimento sócio-econômico, Brasil

\section{AUTOR}

\section{ANTÔNIO TADEU RIBEIRO DE OLIVEIRA}

Pesquisador do IBGE e Pesquisador Associado do Observatório das Migrações Internacionais (OBMigra). Email: 